\title{
ANALISIS DAYA DUKUNG TIANG BOR AKSIAL, LATERAL, DAN PENURUNAN PADA TANAH CLAY SHALE DI SENTUL, BOGOR
}

\author{
Steven Long ${ }^{1}$, Ali Iskandar ${ }^{2}$ dan Sunarjo Leman ${ }^{3}$ \\ ${ }^{1}$ Program Studi Sarjana Teknik Sipil, Universitas Tarumanagara, Jl. Letjen S. Parman No.1 Jakarta \\ Email: steven.l1@stu.untar.ac.id \\ ${ }^{2}$ Program Studi Sarjana Teknik Sipil, Universitas Tarumanagara, Jl. Letjen S. Parman No.1 Jakarta \\ Email: ali.iskandar1999@gmail.com \\ ${ }^{3}$ Program Studi Sarjana Teknik Sipil, Universitas Tarumanagara, Jl. Letjen S. Parman No.1 Jakarta \\ Email: sunarjo@ft.untar.ac.id
}

\begin{abstract}
ABSTRAK
Pembangunan yang dilakukan di atas tanah dasar lempung serpih memiliki perlakuan khusus yang tak dapat disamakan pada tanah umumnya, karena tanah ini dapat kehilangan daya dukung secara mendadak bila tanah terekspose oleh udara dan air yang dapat membuat bangunan rusak. Terlebih jika di daerah Sentul manakala merupakan wilayah berkembang nan pesat namun memiliki tanah dasar lempung serpih. Maka, diperlukan perencanaan daya dukung,dan penurunan serta pelaksanaan konstruksi yang tepat guna mendukung beban struktur tetap aman. Perencanaan daya dukung ini akan ditinjau pada salah satu proyek yang menggunakan kelompok tiang bor yang terletak di Sentul, Bogor. Pada perencanaan ini dibantu program Shaft, Lpile, Group, dan Settle3D. Daya dukung tiang akan tereduksi berkisar 50\% dari perhitungan normalnya ini disebabkan oleh karakter tanah lempung serpih yang mudah kehilangan daya dukungnya. Maka dalam analisanya harus memperhatikan pengaruh strength reduction, dalam hal ini kuat geser tak teralir menjadi $135 \mathrm{KPa}$ menghasilkan daya dukung izin $710 \mathrm{KN}$ untuk tiang D80 dan 950KN D100 sehingga menggunakan 258 tiang bor guna mendukung beban, sehingga defleksi saat siklik menjadi $3 \mathrm{~mm}$, dan penurunan berkisar $45 \mathrm{~mm}$.
\end{abstract}

Kata kunci: lempung serpih, strength reduction, daya dukung, penurunan

\section{PENDAHULUAN}

\section{Latar Belakang}

Maraknya pembangunan yang dilakukan pemerintah Bogor dan investor dalam membangun infrastruktur daerah Bogor membuat persoalan geoteknik. Pada bidang geoteknik, berbagai masalah terjadi seperti tanah longsor, tanah ekspansif, tanah lunak, dan sebagainya. lempung adalah jenis tanah yang bersifat kohesif dan plastis, sedangkan pasir digambarkan sebagai tanah yang tidak kohesif dan tidak plastis, serta jenis tanah berkarakteristik khusus seperti clay shale (Hary, 2002).

Clay shale tersusun dari mineral-mineral lempung yang mempunyai karakter kembang susut yang besar apabila terjadi perubahan kadar air. Tanah akan mengembang (Swelling) pada kondisi basah dan akan menyusut (Shrinkage) pada kondisi kering. Keberadaan clay shale sangat tidak stabil meskipun berada pada kontur yang landai. Clay shale sering dijumpai dalam struktur tanah di Indonesia.

Banyaknya kegagalan Fondasi di atas tanah clay shale yang disebabkan berkurangnya daya dukung, dan longsor secara tiba-tiba karena penurunan kuat geser clay shale. Perencanaan struktur bawah untuk suatu konstruksi bangunan dengan tepat diperlukan untuk dapat menjaga kestabilan konstruksi yang ditahan. Kesalahan dalam perencanaan struktur bawah akan menyebabkan bangunan yang kokoh pada struktur atas menjadi runtuh dan berakibat fatal bagi penghuninya.

Salah satu proyek di Bogor menjadi perhatian penulis karena jenis tanah dilokasi tersebut clay shale. Pada studi kasus ini akan merencanakan daya dukung aksial dan lateral menggunakan program Lpile dan Group, settlement dengan Fondasi tiang kelompok dapat disimulasi Settle3D.

Hasil perencanaan ini dapat menambah kewaspadaan dalam mendesain fondasi pada tanah clay shale, agar dapat mencegah kegagalan fondasi akibat dari sifat tanah. Serta dapat menjadi rujukan pada penelitian selanjutnya.

\section{Batasan Masalah}

Adapun batasan-batasan masalah yang dibahas dalam penelitian untuk menangani kasus ini adalah:

1. Lokasi yang ditinjau Sentul, Bogor, Jawa Barat.

2. Parameter tanah berdasarkan soil investigation yang didapatkan dari pihak terkait. 
3. Konfigurasi dan spesifikasi fondasi tiang kelompok dari pihak terkait.

4. Jenis tanah dasar clay shale.

5. Data pendukung menggunakan data sekuder.

6. Pengeboran dengan metode dry boring.

7. Tidak meperhitungkan gempa.

8. Lapisan tanah kohesif.

\section{Rumusan Masalah}

Rumusan masalah yang dibahas pada makalah ini, adalah:

1. Perencanaan daya dukung aksial single pile and group piles.

2. Perencanaan daya dukung lateral single pile and group piles.

3. Analisis penurunan fondasi.

\section{Tujuan Dan Manfaat Penelitian}

Maksud penulisan ini adalah untuk studi mengenai perbedaan daya dukung tanah. Sedangkan tujuan penulisan ini adalah untuk mengidentifikasi dan meningkatkan kewaspadaan pada analisa daya dukung tiang tunggal maupun tiang kelompok dan pernurunan fondasi.

\section{LANDASAN TEORI}

\section{Daya Dukung Aksial Tiang Bor}

Daya dukung tiang bor dapat diekspresikan dalam persamaan berikut:

$$
Q_{u}=Q_{p}+Q_{s}-W_{p}
$$

Dengan $\mathrm{Q}_{\mathrm{u}}=$ Daya dukung ultimit tiang, $\mathrm{Q}_{\mathrm{p}}=$ Kapasitas ultimit tahanan ujung, $\mathrm{Qs}=$ Kapasitas ultimit geser selimut

\section{Daya Dukung Ujung}

\section{Metode Aurora \& Reese}

Pada tahun 1976 Aurora \& Reese melakukan penelitian daya dukung aksial tiang bor pada tanah clay shales, merekomendasikan daya dukung ujung seperti persamaan berikut,

$$
q_{p}=C_{q} \cdot N_{c}
$$

dimana:

$$
C_{q}=\frac{N_{60}}{55}
$$

Dengan $\mathrm{C}_{\mathrm{q}}$ = shear strength (tsf), $\mathrm{N}_{\mathrm{c}}=7$, bila tiang bor dibuat dengan metode wash boring, $\mathrm{N}_{\mathrm{c}}=8$, bila tiang bor dibuat dengan metode dry boring.

\section{Daya Dukung Selimut}

\section{Metode Aurora \& Reese}

Aurora \& Reese merekomendasikan untuk tahanan selimut pada clay shale sebagai berikut,

$$
Q s=\alpha \cdot C_{q} \cdot A_{s}
$$

Dengan, $\alpha=0.5$; bila tiang bor dibuat dengan metode wash boring, $\alpha=0.75$; bila tiang bor dibuat dengan metode dry boring, $\mathrm{A}_{\mathrm{s}}=$ Luas selimut tiang.

Akan tetapi pada penelitian Irsyam, dkk (2007) merekomendasikan nilai $\alpha$ 0,375 dengan batasan tegangan selimut berkisar $0,75-1 \mathrm{~N}$.

\section{Metode O’Neill \& Reese}

$$
\begin{aligned}
& \alpha=0,55 \text { untuk } \frac{s_{u}}{P_{a}} \leq 1.5 \\
& \alpha=0.55-0.1\left(\left(\frac{S_{u}}{P_{a}}\right)-5\right) \text { untuk } 1.5 \leq \frac{S_{u}}{P_{a}} \leq 2.5 \\
& \text { Qs= fs. L.p... } \\
& \mathrm{fs}=\alpha . \mathrm{cu}
\end{aligned}
$$

dengan, $\alpha=$ factor adhesi, fs= gesekan selimut tiang, $\mathrm{L}=$ Panjang tiang, $\mathrm{c}_{\mathrm{u}=}$ kohesi tanah. 


\section{Daya Dukung Lateral Dengan Lpile}

Lpile merupakan suatu program komputer untuk menganalisis kapasitas perpindahan lateral dari tiang pancang yang dikembangkan secara numerik oleh Ensoft, Inc. di bawah arahan Dr. Lymon C. Reese dan pertama kali didistribusikan secara komersial pada tahun 1987. Lpile 2017 menggunakan dua langkah analisis yang saling berhubungan untuk memberikan informasi tentang perilaku tiang yang diberi pembebanan lateral. Hasil keluaran program Lpile 2017 berupa p-y curve serta beberapa perilaku tiang yang digambarkan dalam grafik, seperti hubungan antara beban dengan defleksi yang terjadi pada setiap kedalaman, bending moment, serta shear force yang terjadi pada tiang tersebut. Solusi persamaan untuk perilaku tiang tertentu di bawah pembebanan lateral harus diselesaikan dengan iterasi karena fungsi respons tanah nonlinier dari defleksi tiang.

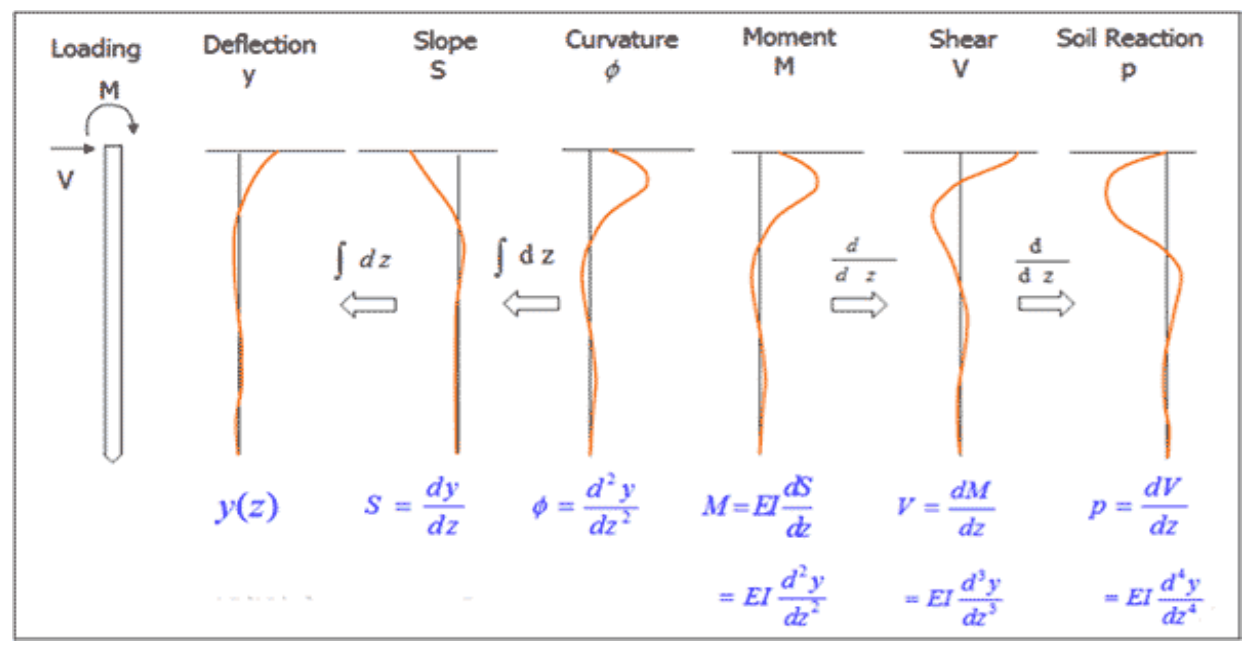

Gambar 1 Persamaan Lpile

\section{Efisiensi Kelompok Tiang Aksial}

1. Metode Converse-Labarre

$$
E_{g}=1-Q \frac{(n-1) m+(m-1) n}{90 m n}
$$

Dengan, $\mathrm{Q}=\tan (\mathrm{d} / \mathrm{s})\left(^{\circ}\right), \mathrm{d}=$ diameter tiang, $\mathrm{s}=$ jarak antar as tiang, $\mathrm{n}=$ jumlah tiang dalam baris , $\mathrm{m}=$ jumlah baris

2. Metode Los Angeles

$$
E_{g}=1-\frac{D}{\pi \cdot s \cdot m \cdot n} \cdot[m(n-1)+n(m-1)+(m-1)(n-1) \sqrt{2}]
$$

Dengan besaran yang sama dengan sebelumnya.

3. Metode Feld

Kapasias tiang berkurang sebesar 1/16 akibat adanya tiang berdampingan baik arah tegak lurus maupun dalam arah diagonal.

\section{Efisiensi Kelompok Tiang Lateral dengan Group}

Group adalah program untuk menganalisis perilaku kelompok tiang yang mengalami pemuatan aksial dan lateral. Program ini dikembangkan untuk menghitung distribusi beban (vertikal, lateral, dan menjungkirbalikkan momen hingga tiga sumbu ortogonal) yang diterapkan dari berbagai lokasi di pile cap hingga pile yang disusun dalam kelompok.

Program ini menghasilkan secara internal respon nonlinear dari tanah, dalam bentuk kurva t-z dan Q-w untuk pembebanan aksial, dalam bentuk kurva p-y untuk pembebanan lateral dan dalam bentuk kurva T-q untuk pembebanan torsional. Suatu solusi membutuhkan iterasi untuk mengakomodasi respons nonlinier dari setiap tiang dalam model kelompok. Program Group memecahkan respons nonlinier dari masing-masing tiang dengan beban gabungan dan memastikan kompatibilitas deformasi dan keseimbangan gaya antara beban eksternal yang diterapkan dan reaksi dari masing-masing kepala tiang.

Untuk tiang dengan jarak yang berdekatan, interaksi tiang-tanah-tiang (efek kelompok) dapat diperhitungkan dengan memperkenalkan faktor reduksi untuk kurva p-y yang digunakan untuk setiap tiang tunggal. Sebagai pilihan, pengguna dapat meminta program untuk secara otomatis menghasilkan saran pengganda $\mathrm{p}$ untuk pengurangan internal ketahanan tanah pada tiang dengan jarak dekat. 


\section{Penurunan Fondasi dengan Settle3D}

Program tiga dimensi yang dikembangkan oleh Roscience untuk analisis konsolidasi vertikal dan penyelesaian di bawah fondasi, tanggul, dan beban permukaan. Program ini menggabungkan kesederhanaan analisis satu dimensi dengan kekuatan dan kemampuan visualisasi dari program tiga dimensi yang lebih canggih.

Dapat dengan cepat membuat profil tanah yang rumit dan kondisi pemuatan, dan melihat hasilnya dalam tiga dimensi. Pemodelan dapat ditampilkan, dan analisis konsolidasi tergantung waktu dapat dilakukan termasuk konsolidasi primer dan sekunder (creep) pada interval waktu yang ditentukan pengguna. Bahan linier dan non-linear dapat dimodelkan. Ketinggian air tanah dapat ditampilkan, dan kondisi drainase horizontal dan vertikal dapat ditentukan.

Bentuk-bentuk beban melingkar, persegi panjang atau poligonal dapat didefinisikan dengan besaran beban seragam atau variabel, dan fondasi yang fleksibel atau kaku. Memuat dapat dipentaskan dan diterapkan pada kedalaman apa pun (misal untuk mensimulasikan pondasi tiang pancang atau rakit). Penggalian dapat ditentukan, dan beban diterapkan dalam area yang digali. Perancang tanggul khusus memungkinkan Anda untuk dengan mudah menentukan tanggul berlapis multi-tahap. Opsi analisis Kembali memungkinkan Anda untuk menentukan ketinggian atau waktu pengisian pra-muat yang diperlukan untuk mencapai penyelesaian tertentu.

\section{METODOLOGI PENELITIAN}

\section{Diagram Alur Penelitian}

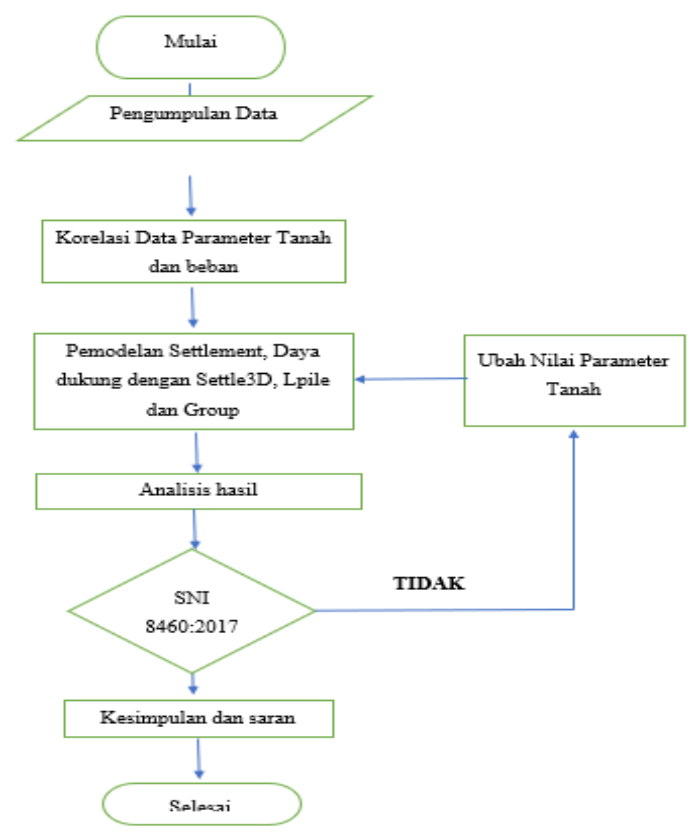

\section{ANALISIS DAN PEMBAHASAN}

\section{Data Tanah}

Lokasi proyek berada di Sentul, Bogor dengan luas bangunan 60x60, dengan titik 6 titik uji tanah SPT dan CPT diperoleh hasil penyelidikan tanah sebagai berikut: 

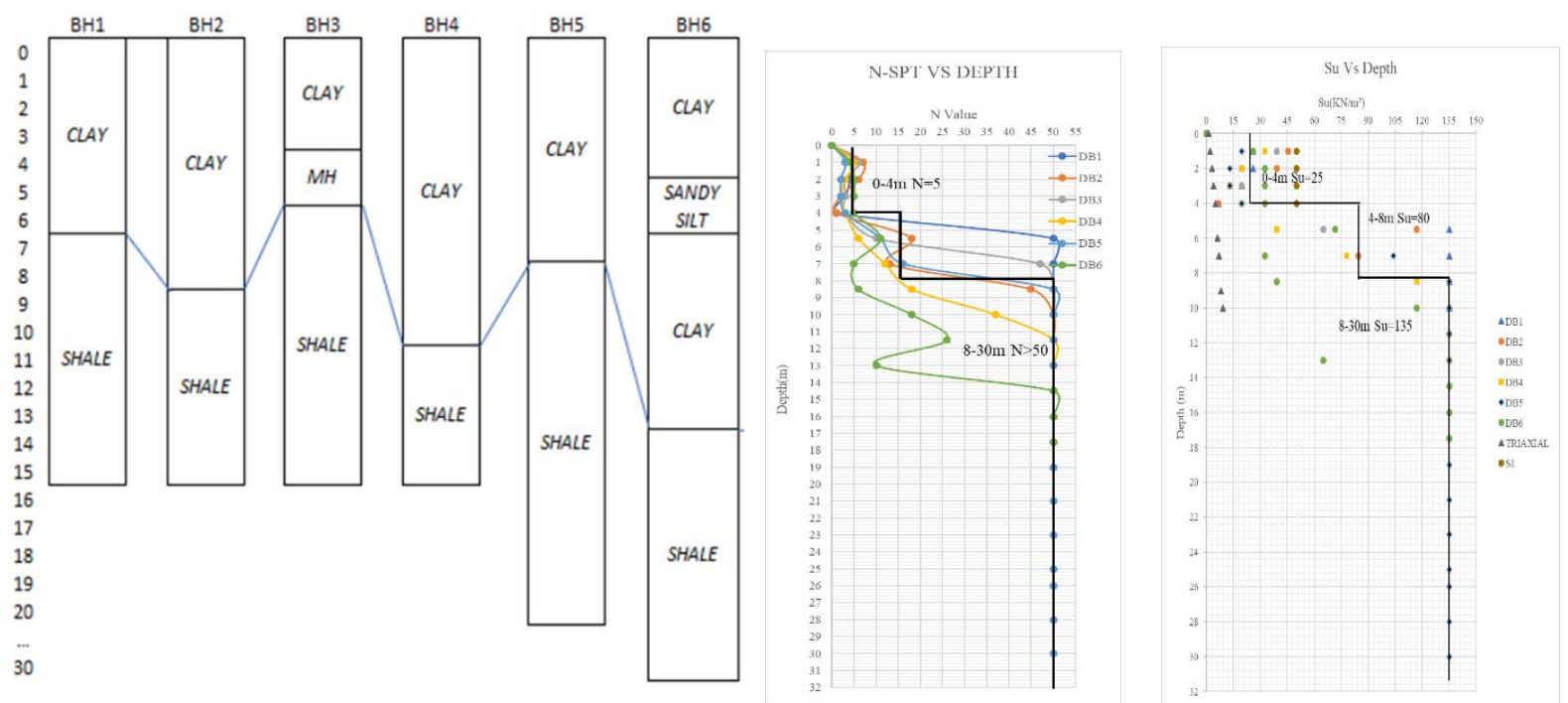

Gambar 2 Data Penyelidikan Tanah

Pengambilan parameter Su merupakan hal krusial dimana clay shale akan mengalami strength reduction effect saat pelaksaan konstruksi maka dari itu Irsyam, dkk merekomendasikan bahwa parameter Su yang menurut Terzaghi 6,5N harus direduksi menjadi 2N- 2,7N untuk mengantisipasi kegagalan tiang yang diakibatkan clay shale.

Dimana fluktuasi muka air tanah berperan aktif pada tingkat kestabilan struktur clay shale itu sendiri. Bila mana terjadi fluktuasi muka air tanah hingga lapisan clay shale maka harus diperhitungkan reduksi daya dukung yang disebabkan dari proses pelapukan, dimana menurut Idrus clay shale Sentul memiliki rasio disintergritas 0,92 masih durable bila tidak terganggu dari proses pelapukan.
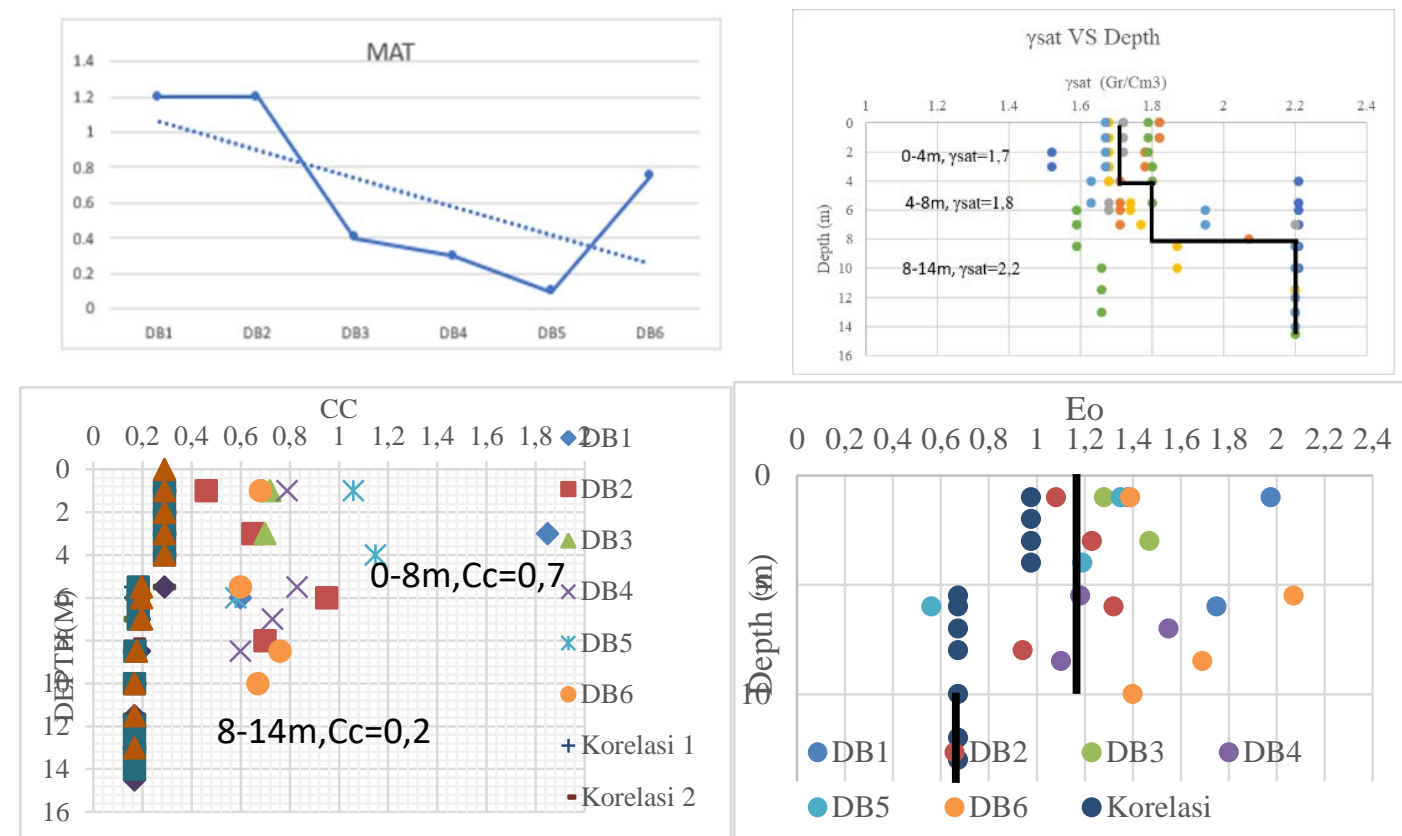

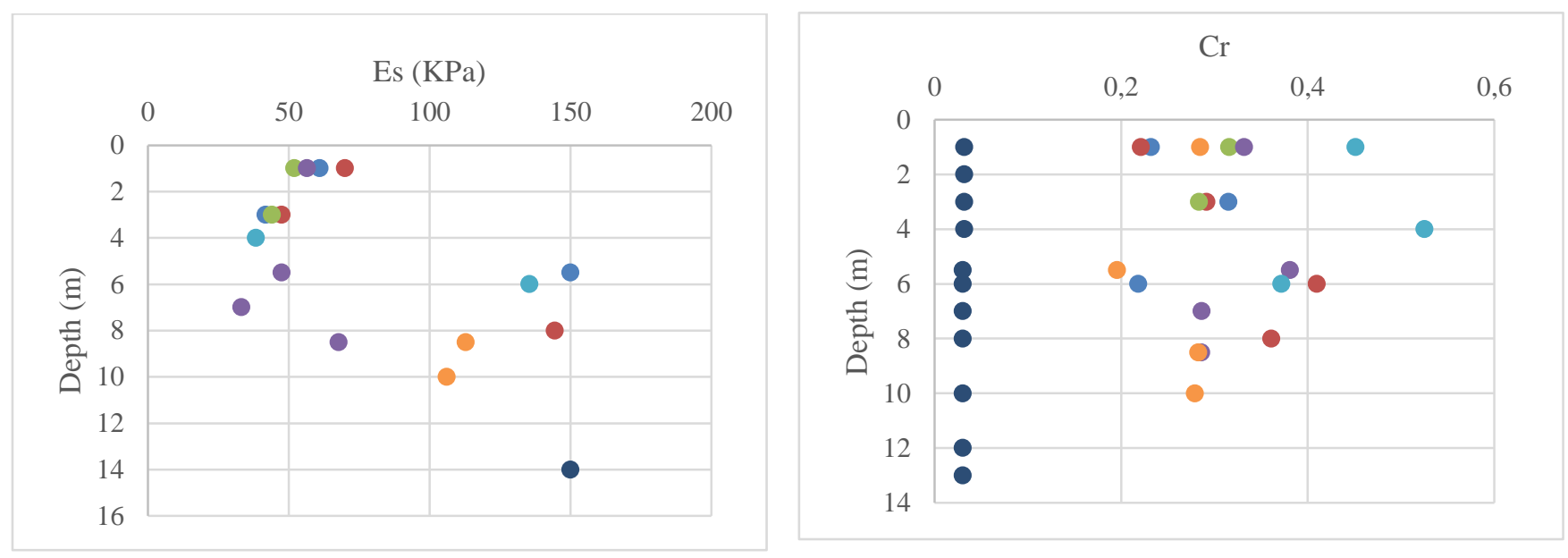

Gambar 3 Parameter Tanah Dan Korelasi

\section{Analisis Daya Dukung Tiang}

Analisis menggunakan Shaft dan membandingkan jika tanah dasar berupa clay dan shale didapat hasil daya dukung sebagai berikut. Tiang menggunakan 2 diameter 100 dan 80 cm, dengan kedalaman hingga 18 meter.
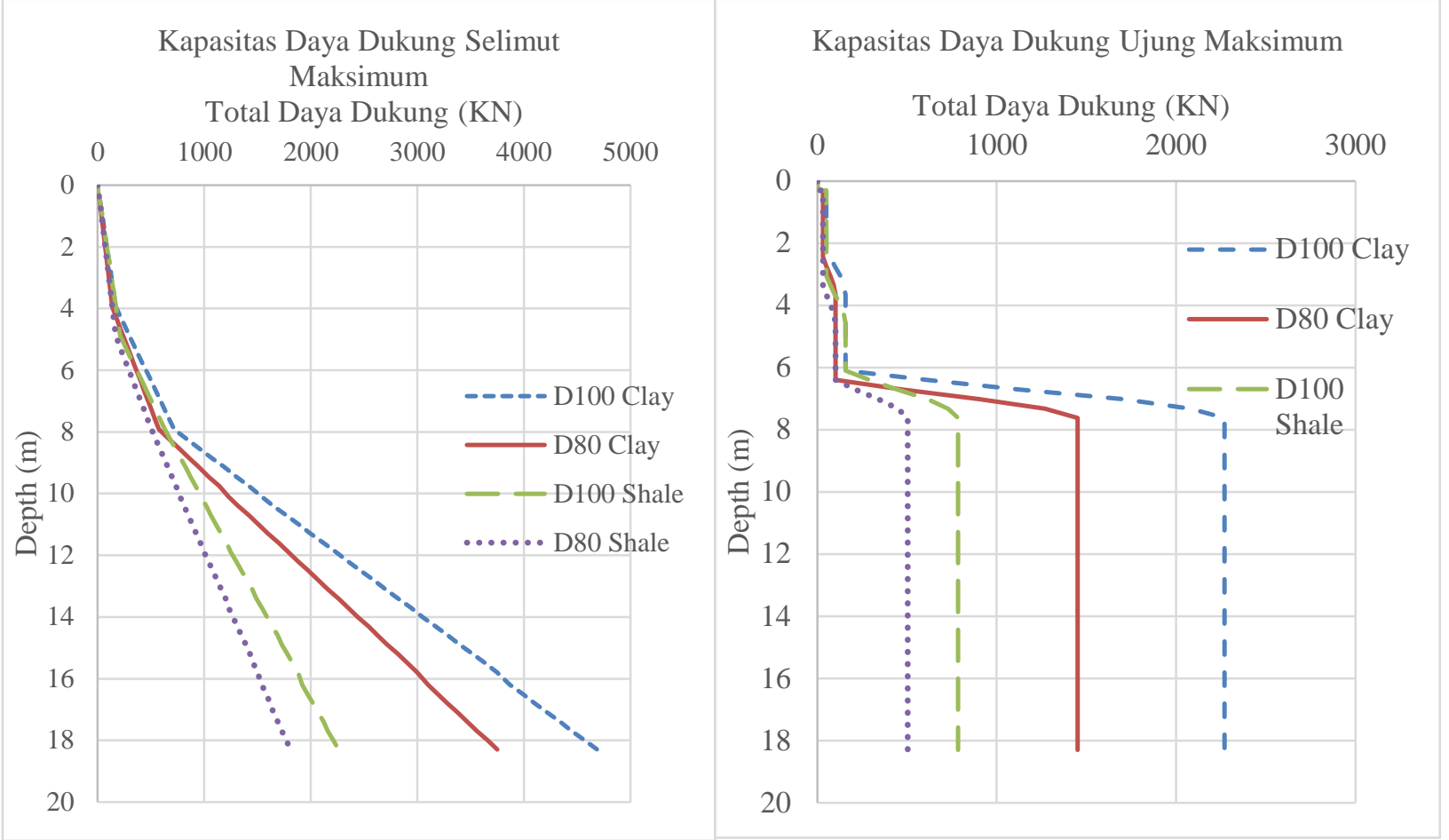

Gambar 4 Daya Dukung Tiang Bor

Perbedaan yang signifikan ini disebabkan parameter kuat geser tidak teralir, dimana bila tanah shale dianggap sebagai tanah clay akan berakibat kegagalan fondasi. Pembatasan tagangan ujung direkomendasikan menurut Goodman sebesar $1000 \mathrm{KPa}$. 

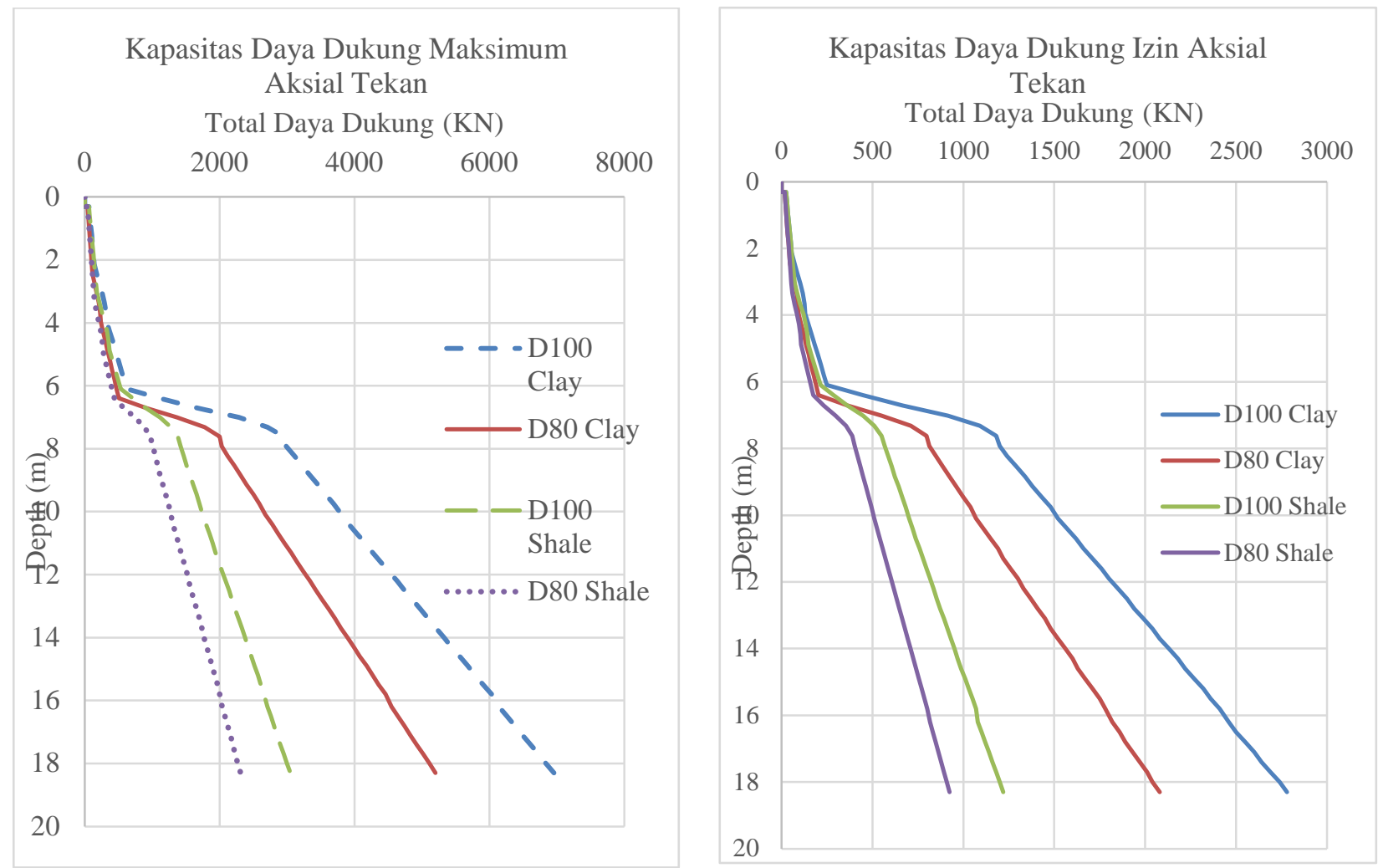

Gambar 5 Daya Dukung Total Aksial

Untuk faktor keamanan menggunakan 2,5 karena mempertimbangkan bahwa pelaksanaan konstruksi diawasi dengan ketat dan seksama. Untuk desain penulis menggunakan daya dukung pada kedalaman 14 meter, karena tiang direncanakan pada kedalaman 14 meter. Berikut perbandingan daya dukung izin terhadap hasil uji pembebanan.
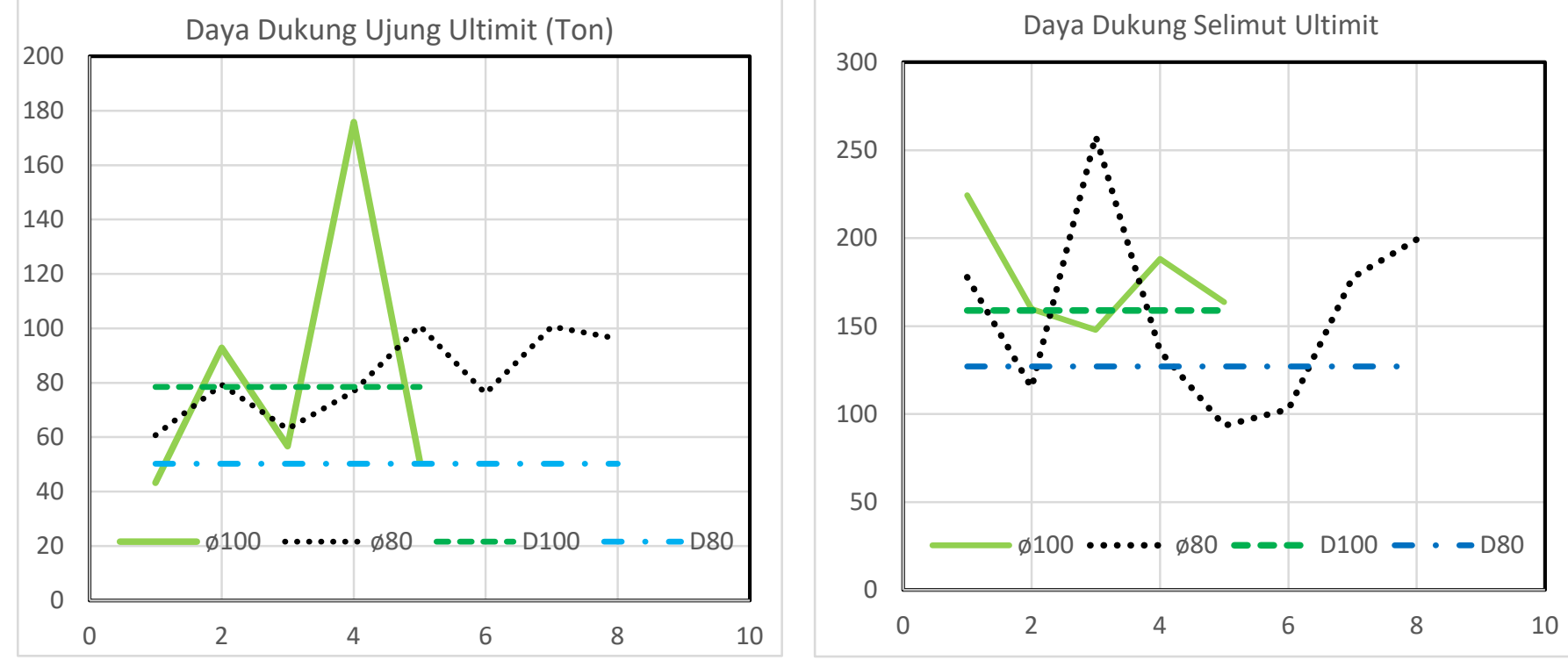

Gambar 6 Perbandingan Daya Dukung Ultimit Desain terhadap PDA 


\section{Analisis Daya Dukung Lateral Lpile}

Penulis menggunakan metode trial error dimana tiang diberikan defleksi 2 mm hingga 34 mm untuk menentukan daya dukung tiang, serta mereduksi tiang dari 0 hingga $90 \%$.

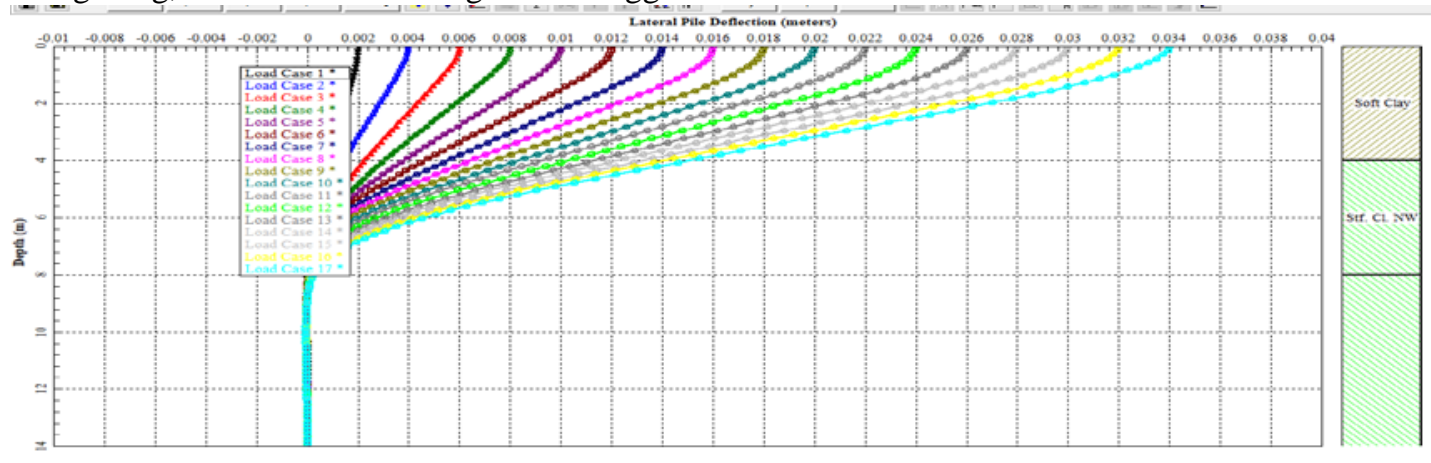

Gambar 7 Defleksi Lpile Tiang D100

Berdasarkan hasil Analisa defleksi Lpile lapisan tanah clay shale dapat diabaikan dari kedalaman 8 m ke bawah, karena defleksi hanya di kedalaman 8m, berarti tekanan tanah hanya bereaksi dari permukaan sejauh 8D. Berikut daya dukung lateral tiang tunggal.
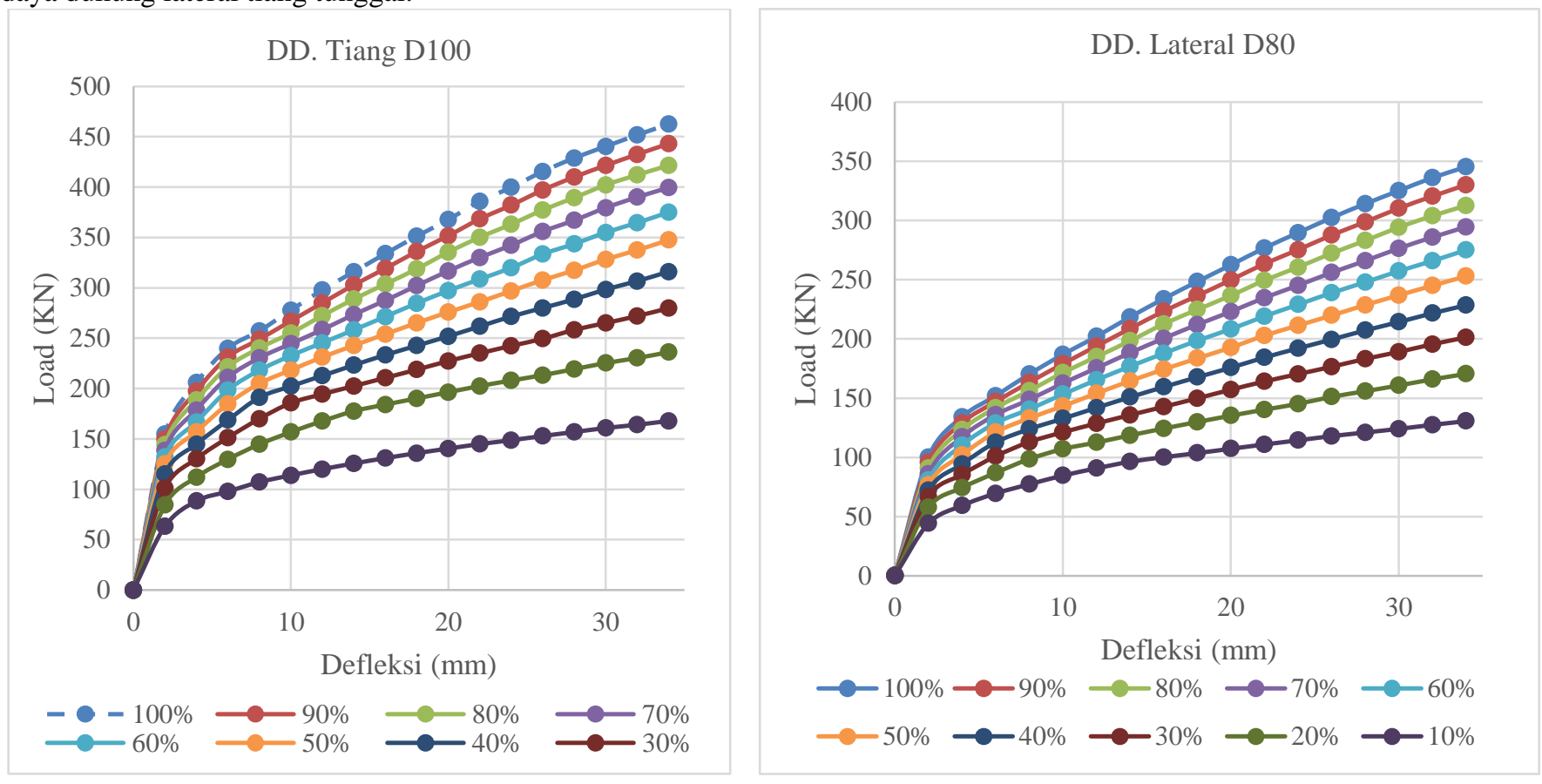

Gambar 8 Daya Dukung Lateral Tiang Tunggal

\section{Analisis Tiang Kelompok}

Konfigurasi tiang terdiri dari 2 tiang dan 3 tiang, dengan jumlah keseluruhan 258 tiang didapatkan efisiensi tiang baik aksial dan lateral dengan Group didapat sebagai berikut. 
Tabel 1 Daya Dukung Tiang Kelompok

\begin{tabular}{ccccccc}
\hline Pile Cap & Dia. & $\begin{array}{c}\text { Jumlah } \\
\text { tiang }\end{array}$ & $\begin{array}{c}\text { Efisiensi } \\
\text { kelompok } \\
\text { tiang }\end{array}$ & $\begin{array}{c}\text { DD. } \\
\text { Aksial } \\
\text { Kel. } \\
\text { Tiang } \\
(\mathrm{KN})\end{array}$ & $\begin{array}{c}\text { Jumlah } \\
\text { Pile cap }\end{array}$ & DD. Total \\
\hline 1 & 80 & 2 & 0.9 & 1278 & 67 & $(\mathrm{KN})$ \\
\hline 2 & 80 & 3 & 0.87 & 1853.1 & 13 & 24090.3 \\
\hline 3 & 100 & 2 & 0.9 & 1710 & 38 & 64980 \\
\hline 4 & 100 & 3 & 0.87 & 2479.5 & 3 & 7438.5 \\
\hline
\end{tabular}

Sedangkan untuk efisiensi lateral didapat untuk masing-masing tiang berkisar antara 0,6 sampai 0,93. Sehingga didapatkan grafik kapasitas lateral tiang kelompok terhadap defleksi seperti gambar berikut.

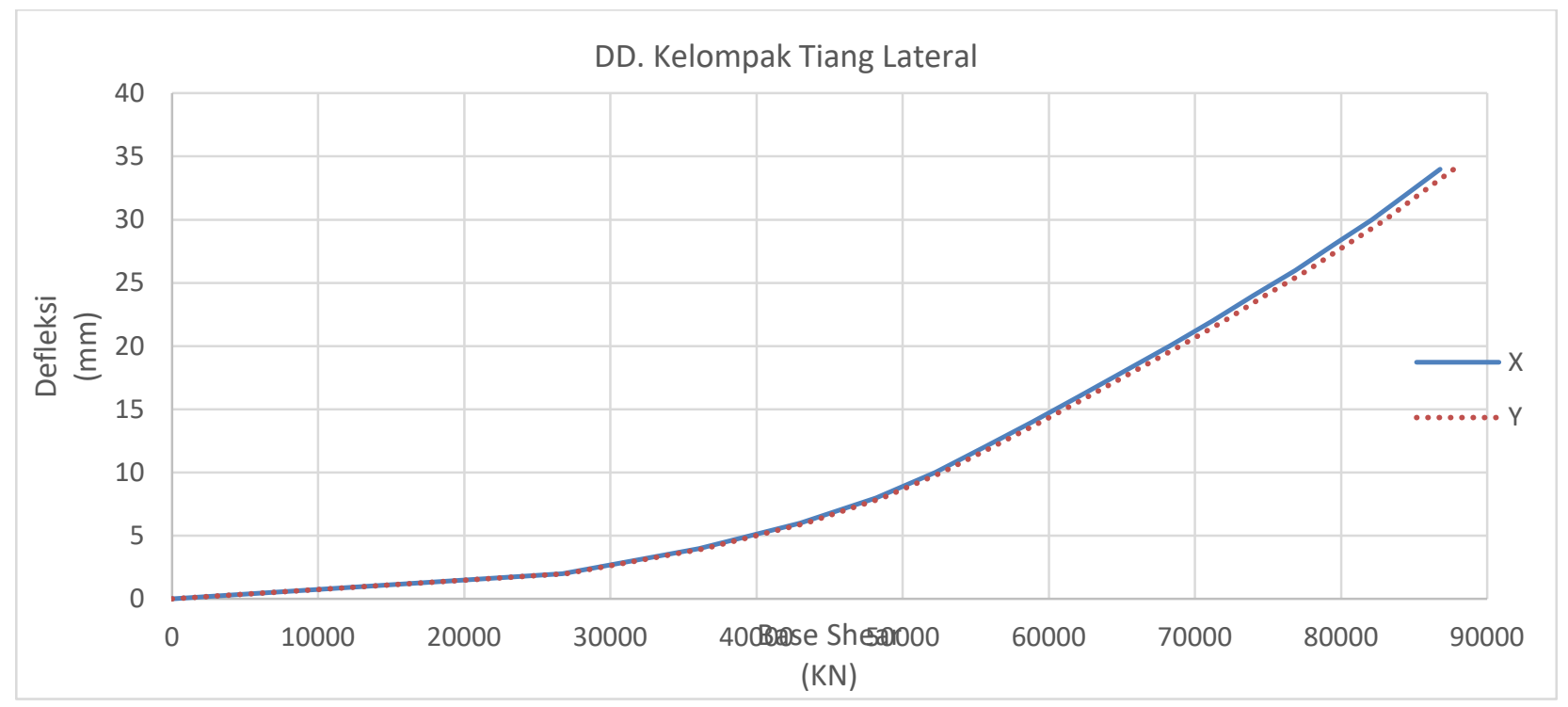

Gambar 9 Kapasitas Lateral Tiang Kelompok

\section{Analisis Penurunan}

Analisis penurunan dilakukan berdasarkan hasil analisis Settle3D dengan parameter tanah clay shale berupa korelasi, didapatkan penurunan maksimum 45 mm dengan kontur penurunan seperti gambar berikut ini. Penurunan terjadi berdasarkan kondisi tiap lapisan tanah clay shale yang bervariasi dimana semakin ke pojok kanan bawah lapisan clay shale berada dikkedalaman 10 meter.

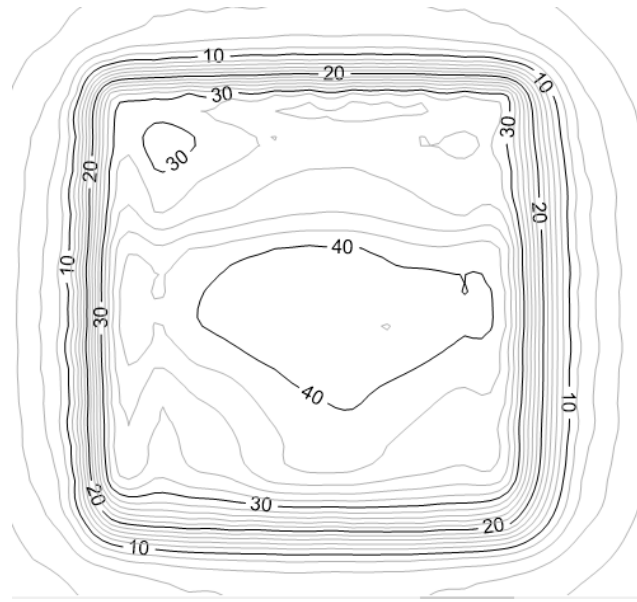

Gambar 10 Penurunan Total 


\section{KESIMPULAN}

1. Daya dukung lateral didapatkan dari defleksi yang terjadi berbasiskan kapasitas base shear tiang kelompok yang sudah memperhitungkan faktor reduksi lateral dengan base shear saat terjadi beban siklik dimana SNI 8460:2017 pasal 9.7.3.1 membatasi defleksi lateral $12 \mathrm{~mm}$ ketika gempa nominal. Defleksi yang terjadi pada struktur hanya 2 mm untuk gempa nominal dan $3 \mathrm{~mm}$ gempa kuat.

2. Daya dukung kelompok tiang memikul beban aksial sebesar 182.134, $8 \mathrm{KN}$.

3. Penurunan total yang terjadi $44 \mathrm{~mm}$.

4. Terdapat perbedaan daya dukung signifikan jika mengganggap clay shale sebagai tanah lempung.

5. Pelaksanaan konstruksi dengan metode dry boring dan pengecoran dalam waktu singkat akan mengurangi strength reduction effect akibat teraksposenya clay shale.

6. Proses pelapukan pada clay shale dapat diabaikan dikarenakan muka air tanah berkisar kedalaman 0- 1,5 meter, maka memiliki durabilitas cukup baik.

7. Analisis lateral pada clay shale dapat dianggap clay bilamana lapisan clay shale tidak berdefleksi akibat tiang, pada kasus ini tiang hanya berdefleksi 8D (8 meter)

\section{SARAN}

Berdasarkan hasil analisis yang telah dilakukan, perlu adanya penelitian lebih lanjut untuk mengetahui penyebab perbedaan daya dukung ujung pada tanah lempung serpih, dan untuk mengetahui penurunan lebih lanjut dapat menggunakan parameter hasil uji laboratorium terhadap lempung serpih.

\section{DAFTAR PUSTAKA}

Alatas, M Idrus. Pengaruh Proses Pelapukan Clay Shale Terhadap Perubahan Parameter Rasio Disintegritas Jurnal Teknik Sipil: Issn 0853-2982.

Aurora, P.L And Reese, C.L. 1976. Behavior Of Axially Loaded Drilled Shafts In Clay-Shales. Publikasi Cfhr 3-572-176-4. Texas: Texas State Department Of Highways And Public Interim Transportation.

Brown, Dan A., John P. Turner, Raymond J. Castelli. 2010. Drilled Shafts: Construction Procedures And Lrfd Design Methods. Publikasi Fhwa Nhi-10-016. Washington, D.C : Federal Highway Administration.

Goodman, Richard E. 1989. Introduction To Rock Mechanics 2nd Edtion. New York : John Wiley \& Sons,Inc.

Group User Manual. The America. 2016

Hardiyatmo, Hary Christady. 2002. Mekanika Tanah 1. Yogyakarta: Universitas Gadjah Mada Press.

Irsyam, Mansyur, Dkk. 2007. Pengaruh Strength Reduction Tanah Clay-Shale Akibat Pelaksanaan Pemboran Terhadap Nilai Daya Dukung Pondasi Tiang Di Jembatan Suramadu Berdasarkan Analisis Hasil Tes Oc. Jurnal Teknik Sipil: Vol.14 No.2.

Lpile User Manual. The America. 2018

Meyerhof G.G., 1976, “Bearing Capacity and Settlement of Pile Foundations”, ASCE JGED, Vol. 102, No. GT 3 , March, pp. 196-228.

Reese, C.L. \& William M.I., Shin T.W.. 2006. Analysis And Design Of Shallow Foundation And Deep Foundatin. New York : John Wiley \& Sons.

Sanglerat, Guy. 1972. The Penetrometer And Soil Exploration. Elsevier Publishing Company. 